\title{
Pre-exposure to Food Temptation Reduces Subsequent Consumption: A Test of the Procedure with a South-African sample
}

\author{
Helen Duh, Aiste Grubliauskiene \& Siegfried Dewitte
}

\section{Accepted at APPETITE}

\begin{abstract}
Author notes
Helen Inseng Duh, PhD (corresponding author). Senior Lecturer. Department of Marketing, School of Economic and Business Sciences, University of Witwatersrand, 1 Jan Smuts Avenue, Braamfontein, 2000, Johannesburg - South Africa. Email: duhhelen@ yahoo.com; tel Tel: 27 834452540

Aiste Grubliauskiene, PhD, Postdoctoral Researcher, Behavioral Engineering Reseach Group, Faculty of Business and Economics, KU Leuven, Naamsestraat 69, 3000 Leuven, Belgium. Email: Aiste.Grubliauskiene@kuleuven.be

Siegfried Dewitte, $\mathrm{PhD}$, professor Marketing, Behavioral Engineering Reseach Group, Faculty of Business and Economics, KU Leuven, Naamsestraat 69, 3000 Leuven, Belgium. Email:

Siegfried.dewitte@kuleuven.be
\end{abstract}

The three authors contributed equally to this report. The contribution of the second and third author was supported by EU-funded collaboration FP-7 project TEMPEST. We thank anononymous reviewers for valuable feedback on earlier versions of this paper. 


\begin{abstract}
It has been suggested that the consumption of unhealthy Westernized diet in a context of poverty and resultant food insecurity may have contributed to South-Africa's status of the third fattest country in the World. Considering that a number of South-Africans are reported to have experienced, or are still experiencing food insecurity, procedures which have been shown to reduce the consumption of unhealthy food may be ineffective in South-Africa. We thus tested the robustness of the so called pre-exposure procedure in South-Africa. We also tested the moderating role of childhood poverty in the pre-exposure procedure. With the pre-exposure procedure, a respondent is exposed to a tempting unhealthy food (e.g. candy) in a context that is designed such that eating the food interferes with a task goal. The typical result is that this procedure spills over and reduces consumption of similar tempting food later on. An experimental study conducted in a South-African laboratory showed that the pre-exposure effect is robust even with a sample, where food insecurity prevails. Childhood poverty did not moderate the effect. This study proves that behavioral procedures aimed at reducing the consumption of unhealthy food would be valuable in less rich non-Western countries. Further testing of the robustness of the pre-exposure effect is however recommended in other poorer food insecure countries.
\end{abstract}

Keywords: food security; obesity; poverty; tempting food; pre-exposure procedure; South Africa

\title{
Introduction
}

Two decades after the entry of Western fast-food chains in South Africa, Birrell (2014) reports that a once skinny teenager, named Thando grew into "a 5'5" man weighing almost 17 stone (i.e., about $170 \mathrm{~kg}$ ) . Thando now struggles to find clothes to fit his inflated body and complains that seats are becoming too small for comfort". Thando feels that his situation is exacerbated by the common belief in South Africa that "if you have a one-pack big belly, like a 
beer belly, you must have lots of money, but if you have a six-pack, there is something wrong" (Birrell, 2014).

Thando is not the only person with an obesity problem in South-Africa. The arrival of Western fast-food restaurants and the introduction of Western diets in low and middle income countries, such as South-Africa have triggered the current health epidemic (Popkin et al., 2012). Western diet is defined as "high intakes of refined carbohydrates, added sugars, fats, and animalsource foods" (Popkin et al., 2012, p. 8). The Lancet report of 2014 (see vol. 384, p. 766-781) shows that South-Africa is the world's third fattest nation with about two-thirds of the population being overweight. Despite being one of the wealthiest countries in Africa, about $14 \%$ of the population struggles with food insecurity daily (Koch, 2011). Popkin et al. (2012) contend that food insecurity, low education and many issues associated with poverty are some drivers of obesity. These factors, they further note, increase the vulnerability to the appeal of westernized diets, which offer a good calories/price deal but are poor in essential nutrients.

As high-calorie food consumption and obesity is also one of the major health threats in wealthy Western countries, behavioral scientists have studied factors that drive the overconsumption of high-caloric food and have explored and found procedures to reduce its consumption. Because South-Africa differs in many respects from the populations in which such procedures have been designed, it remains an open question as to whether the procedures shown to enhance resistance to unhealthy food in richer well-fed populations would be of any significance in poorer populations experiencing food insecurity.

In this paper we tested the effectiveness of the pre-exposure procedure, which has been shown to reduce the consumption of unhealthy tempting food. The common finding is that the consumption of tempting food is reduced after exposure to it on either pictures or physically (Geyskens et al., 2008). In a Western country, the pre-exposure procedure has, for example, been tested using Belgian sample (Geyskens et al., 2008; Grubliauskiene \& Dewitte, 2014; De Boer et al., 2015). Considering that South-Africa's population has relatively lower SES than Western countries, and the prevalence of food insecurity can create a stronger temptation to consume unhealthy food, this paper tests whether the pre-exposure procedure is applicable with a SouthAfrican sample. 
The paper is organized as follows. We first review the relevant literature by introducing the need and dynamics of the pre-exposure procedure. We then test the pre-exposure procedure with South-Africans. We end the paper with a discussion on the policy implications and avenues for further research.

\section{Literature Review}

\section{The Need and dynamics of the pre-exposure procedure}

People in developed, as well as developing countries are increasingly confronted with unhealthy, yet highly tempting foods, such as ice cream, various pies, burgers, potato chips, chocolates, pizzas, fried chicken, candies, etc., which they often disproportionately consume (Brownnell \& Hoegen, 2004; Kroese et al., 2009) and may contribute to the alarming worldwide obesity epidemic among adults and children (Popkin et al., 2012).

To curb the overconsumption of unhealthy food, interventions are needed. One of the proposed interventions is to restrict the consumption of unhealthy food. This intervention has usually been guided by Metcalfe and Mischel's (1999) hot/cool theory, which posits that food temptations activate a 'hot', impulsive system. As people impulsively succumb to the temptation, the 'cool' and rational system, which represents long-term health goals, is rendered powerless. With this notion, the exposure and access to tempting foods, especially among the youths have been restricted. Unhealthy foods have been substituted in vending machines with healthy ones (Hagger \& Luszczynska, 2013; French et al., 2003). These restrictions do not only render the somewhat "forbidden fruit" more enticing, but these types of interventions, especially made in homes and school environments may succeed only as long as the restriction holds. More so, there may be inability to resist temptation in environments where restrictions are absent. Selfregulation skills may therefore, be needed in this case (De Vet et al., 2013).

An approach which enhances the development of self-regulation skills in the presence of tempting food is the pre-exposure procedure. It is in accordance with Trope and Fishbach's (2000) counteractive control theory, which stipulates that exposure to food temptation, helps rather than hurts the resistance to unhealthy food temptation. According to this theory, the presence of a temptation activates the chronic food restriction goal, which in turn facilitates adaptive self-regulation (Fishbach et al., 2003; Kroese et al., 2009). Further developments of the 
procedure relaxed the requirement that a chronic food restriction goal was already present (e.g., De Boer et al., 2015; Dewitte, Bruyneel \& Geyskens, 2009; Geyskens et al., 2008;

Grubliauskiene \& Dewitte, 2014).

The adapted pre-exposure procedure, which is the focus of this paper, exists in two phases. In the first phase, respondents are (physically) exposed to a tempting food in a context that discourages its consumption, thereby effectively installing a temporal food restriction goal. For instance, the respondents have to engage in a consumer knowledge task, where they have to associate candy wrappings to various flavors. In this task, respondents typically do not eat the candies as consuming would ruin the purpose of the task. The researcher however does not explicitly restrict them from eating the candies.

In the second phase, the respondents move on to a taste test of similar (but not identical) tempting food and can consume the food as much as they wish. The common finding from the experiments is that those who had been exposed to temptation in the previous phase eat less during the taste test, than those who had not been exposed to temptation (Dewitte et al., 2009). Interestingly, this pre-exposure seems to suppress the effect of marketing factors known to boost consumption, such as appealing scents of food or consumption convenience (Geyskens et al., 2008). Another interesting feature of the pre-exposure procedure is that it seems to be independent on the presence of a health goal, a feature which makes the effect amenable for exploitations in populations with a weaker food regulation goal (e.g. men, Grubliauskiene \& Dewitte, 2015; and children, Grubliauskiene \& Dewitte, 2014). The effect has also been shown to be amenable in a school context and exerts its effect after a day's delay (de Boer et al., 2015).

While the pre-exposure procedure has worked in all these contexts, we question its applicability in South-Africa, where poverty and food insecurity prevails. The next section discusses the socio-economic situation in South-Africa, to conceptually assess the applicability of the pre-exposure procedure.

\section{Can the socio-economics of South-Africa warrant the effectiveness of the pre-exposure procedure?}

Looking at economic factors, such as gross domestic product per capita, architectural and technological infrastructure, it is evident that South Africa is an upper-middle-income country. 
When one however looks at social indicators, such as food security, life expectancy, infant mortality and the fact that the poorest one-fifth of South Africans have an average purchasing power similar to those of citizens in the world's poorest countries, South Africa resembles a lowincome country (Van der Berg, 2014). Consequently, about 14\% of South African citizens struggle with food insecurity (Koch, 2011).

Food security, Oldewage-Theron, Duvenage and Egal (2012) stipulate, embodies the concepts of food availability (in sufficient quantities on a consistent basis); food access (sufficiency of resources to acquire suitable foods for a nutritious diet); and food use (proper use based on the right application of basic nutrition and care). Even though nationally there is adequate food supply in South Africa, high level of poverty in many households prevents access to appropriate food supply and nutritious diets (Koch, 2011). In 2011, 20.2\% of South-Africans lived in extreme poverty (food poverty line below which people are unable to purchase enough food for an adequate diet) and $45.5 \%$ lived in moderate poverty (poverty line below which people can afford an adequate diet but would have to sacrifice food to purchase non-food items) (Social Development, 2014).

The households living in extreme poverty are inevitably left with the choice of consuming a monotonous diet consisting mainly of staple starches, such as maize meals, potatoes chips (French fries) and bread with very limited amounts of proteins, fruit and vegetables. The consumption of mainly carbohydrate-based diet with little dietary variety accounts for the current relationship between higher obesity rates and low-income levels in South Africa (OldewageTheron et al., 2012). When children grow up in households where the intake of essential micronutrients was deficient, or when the children were nutritionally deprived, it may lead to a situation, which Oldewage-Theron et al. (2012, p. 54) term a "hidden hunger". Oldewage-Theron et al. (2012) report that many people hold "hidden hunger", because of childhood poverty and resultant food insecurity. The "hidden hunger" may culminate in high appetite for unhealthy foods and less ability to resist unhealthy food temptation. It remains questionable whether the pre-exposure to unhealthy food temptation procedure would help South-Africans' ability to resist food temptations.

The effectiveness of the pre-exposure procedure in South-Africa is particularly questionable for unhealthy food items, such as chocolates, sweets and candies. These food items may be somewhat "delicacies" and highly attractive to many South-Africans, who because of poverty, 
have struggled to afford basic food items such as bread. It is speculated that the attractiveness to food items such as chocolates and candies, which Geyskens et al. (2008) and others have used to test the pre-exposure procedure, may very well overrule the pre-exposure effect. This may be so, because the deprivation and craving for these types of food may be probably stronger than the subtle preference changes that the pre-exposure procedure produces.

The main aim of this study is to therefore test whether the pre-exposure procedure suggested by previous studies in richer and well-fed populations would hold among South-Africans, especially as they have relatively limited food access and diet knowledge and greater need for caloric supply (Hanekom, Venter \& du Toit, 2014).

To achieve this study's objective, we will closely follow the procedure as outlined by Geyskens et al. (2008) and focus on the two core conditions: the condition where respondents are exposed to the temptation in the context of a product knowledge task and the condition without exposure to temptation. After this pre-exposure phase, respondents will be invited to engage in a taste test. We will then measure their free consumption of a similar tempting food as a measure of their (lack of) resistance. Based on our reasoning that the level of poverty may overrule the pre-exposure effect because the motivation to eat the tempting food will be relatively stronger, we will measure the moderating role of childhood and current SES of respondents (Griskevicius et al., 2011). Our hypothesis is explorative. If the pre-exposure effect does not depend on poverty (past or present), then the pre-exposure effect should be replicated. If the pre-exposure

effect does depend on poverty, we should find the pre-exposure effect only for those who did not experience poverty.

\section{Method}

\section{Participants and Design}

After obtaining ethical clearance from the Faculty of Management Ethics Committee at the University of Johannesburg in South Africa, one hundred and nine undergraduate students from the university (a multi-racial and socio-economically diverse South-African university) participated in our study. Eight participants were excluded from the analysis because they did not correctly follow the instructions by either not completing the questionnaire $(n=4)$ or eating the 
candy in the first phase $(n=4)$. The data of the remaining one hundred and one participants were analyzed. Female participants were $69.37 \%$.

The majority of participants were Blacks (85.3\%), who according to Peer et al. (2013), engage most in unhealthy consumption lifestyle. Other respondents were White (4.9\%), Indian/Asian (2.9\%) and Colored (6.9\%). Coloreds are mixed race, who are offspring of Malaysians, Indonesians, Indians, Dutch, and from East and West Africans. They are neither Blacks nor Whites. Almost half $(42.7 \%)$ of the respondents grew up in urban previously advantaged areas. $38.8 \%$ grew up in urban previously disadvantaged areas and the remaining were from rural previously disadvantaged areas (18.4\%). The advantaged areas are those where most of the richer White South-Africans live and the disadvantaged areas are mostly inhabited by poorer Blacks.

This study applied a unifactorial (pre-exposure to temptation: present vs. absent) between-subjects design. The study had two ostensibly unrelated phases: a treatment phase, intended to manipulate exposure to a tempting food, and a food consumption measurement phase during which participants engaged in a taste test with free access to a similar tempting food. We then measured the quantity consumed as a measure of lack of resistance.

\section{Procedure}

Participants entered the lab in groups of $10-20$. They were introduced to the study and were invited to take a seat in front of a computer. The study was run on PCs. Participants were randomly assigned to a pre-exposure to temptation or to a control (no pre-exposure to temptation) conditions.

\section{Pre-exposure to Temptation}

During the first phase, participants were asked to complete an alleged "consumer knowledge task". The task of the pre-exposure to temptation condition was adapted from Geyskens et al. (2008), whereby the participants were informed that a manufacturer of a candy, which comes in different flavors, was interested in consumer knowledge about the taste of the candy. Participants received a sheet with color pictures of "Quality Street" candies, a product also available on the South-African market. In line with a cover story on their PC screen, they were asked to associate 12 pictures of "Quality Street" candies on the sheet with the corresponding flavor of the candies indicated on the screen. A bowl with each of the 12 "Quality Street" candy was brought to each 
participant allegedly because the pictures of candy were not always very clear. Participants in the control condition were not given real candy, but they had to associate 12 colors on the sheet of the paper with corresponding words presented on the computer screen (e.g. grass and green, red and passion). Thus participants in this condition engaged in a similar task but did not have to resist temptation.

\section{Resistance}

The second phase was the same for participants in both conditions. The experiment leader provided one bowl of $300 \mathrm{~g}$. regular $M \& M s$ and one bowl of $300 \mathrm{~g}$. Smarties for a taste test. During the taste test, participants had to compare these two types of candy by tasting each type of candy, answering a number of questions about the candies (e.g., "are they crispy?", "are they hard to resist?") and evaluating them on a one-nine scale anchored at "not at all" and "very much". After participants finished the taste test, an experiment leader inconspicuously weighed the amount of candy consumed by each individual. In addition, participants reported how much they liked candy in general on a scale ranging from 1 to 100 .

\section{Dependent Measure}

In line with previous studies (e.g., Geyskens et al., 2008), we considered the amount of candy consumed during the taste test as an indication of (a lack of) resistance.

\section{Measure of Socioeconomic Status}

At the end of the experiment, respondents' socioeconomic status (SES) was measured by means of a short questionnaire derived from Griskevicius et al.'s (2011) instrument. We measured their childhood and their current SES. Their childhood SES measure comprised of the following three statements: "My family usually had enough money for things when I was growing up"; "I grew up in a relatively wealthy neighborhood"; "I felt relatively wealthy compared to the other kids in my school". The Cronbach's alpha obtained for these three items in this study was .79. The current SES comprised of the following three statements: "I have enough money to buy things I want"; "I don't need to worry too much about paying my bills"; "I don't think I'll have to worry about money too much in the future". As the Cronbach's alpha obtained for these three items in this study was low $(\alpha=.56)$ and did not improve after dropping one of the items ( $\max \alpha=.60$ ), the scale was not further used in the analysis. The participants indicated 
their agreement with these statements on a 7-point scale, with 1 meaning strongly disagree and 7 meaning strongly agree.

\section{Results}

The amount of candy consumed was log transformed. The means of quantity consumed were measured in grams and are reported in grams in brackets in the text. We analyzed the quantity of candy consumed during the taste test (as a measure of (lack of) resistance) as the dependent variable, with pre-exposure to temptation (present or absent) as the independent variable, and with respondents' sex and the liking for candy as control variables by means of an ANCOVA. Respondents' sex was included into the analysis because people's sex often affects the amount of eating (Herman \& Polivy, 2010). The trend is usually that males consume more than females. This was also this study's finding, but the difference in consumption was not significant $(M($ men $)=34.68, S D=24.4 ; M($ women $)=25.71, S D=19.75 ; F(1,97)=2.33, p=$ 0.13). General liking for candy, as rated on a 100-point scale, was significantly and positively related to consumption $(F(1,97)=8.20, p<0.01)$.

In terms of the pre-exposure effect, which was the main test of this study, the participants consumed significantly fewer grams of candies in the pre-exposure to temptation condition $(M$ pre-exposure $=22.60, \mathrm{SD}=17.79)$ than in the control condition $(M$ control $=34.14, \mathrm{SD}=23.41 ; F(1$, $97)=5.83, p=0.02$ ). See Table 1 for the summary of the findings.

Table 1

Summary of main findings and descriptive statistics

\begin{tabular}{lccc}
\hline & Pre-exposure & Control & Difference \\
& & & \\
\hline Consumption (g) & $22.60 \mathrm{~g}(17.79)$ & $34.14 \mathrm{~g}(23.41)$ & $F=5.83, p<0.02$ \\
& & & $\mathrm{Ns}$ \\
Number of women & $36(50.7 \%)$ & $35(49.3 \%)$ & $\mathrm{Ns}$ \\
Number of men & $16(50 \%)$ & $16(50 \%)$ & $\mathrm{Ns}$ \\
& $43(49.4 \%)$ & $44(50.6 \%)$ & $\mathrm{Ns}$ \\
Number of blacks & $8(52 \%)$ & $7(48 \%)$ & $F=8.18, p<0.01$ \\
Number of other race & $4.32(1.4)$ & $3.52(1.4)$ & $F=1.98, p=0.16$ \\
Average childhood SES & $3.78(1.5)$ & $3.41(1.2)$ & \\
Average current SES & & & \\
\hline
\end{tabular}


The significant pre-exposure effect remained unchanged even when only the black participants, the relatively poorer population (Oldewage-Theron et al., 2012; Peer et al., 2013), were included into the analysis ( $M$ pre-exposure $=24.05, \mathrm{SD}=18.75$ vs. $M$ control $=34.76, \mathrm{SD}=$ 22.28; $F(1,81)=4.91, p=0.03)$. This adds to the proof of the robustness of the pre-exposure procedure. To assess the robustness, we added responses from the respondents, who violated the instruction not to eat the candies in the first phase of the procedure. We found that the main effect of the pre-exposure remained the same; $F(1,101)=4.90, p<0.05)$.

We also checked if the randomization was successful (see Table 1). The two conditions did not differ for gender, race, and current SES but those in the pre-exposure condition did report to have had a wealthier childhood (see Table 1). We added childhood SES and its interaction with pre-exposure to temptation as predictors to the model, which was one of our study objectives. Neither the effect of childhood SES was significant $(\mathrm{F}(1,95)=.98, p=0.98)$, nor was its interaction with the pre-exposure to temptation $(F(1,95)=2.56, p=0.11)$. For exploratory reasons and because of the near significance, we took a closer look at the interaction and noticed that if anything, the effect of pre-exposure was stronger among those with a relatively poor childhood SES than among those with a relatively wealthy childhood SES.

Including childhood SES and its interaction with pre-exposure to temptation did not change the effects reported above. Neither the effect of pre-exposure to temptation $(F(1,95)=5.41, p=$ 0.02 ), nor its interaction with the pre-exposure manipulation changed after including childhood SES. This attests to the robustness of the main effect. The effect of $\operatorname{sex}(p=0.18)$ and the covariate effect of general liking for candy $(F(1,95)=8.18, p=0.01)$ remained unchanged as well.

\section{Discussion}

More than $60 \%$ of South Africans live in poverty (i.e., $20.2 \%$ in extreme poverty and $45.5 \%$ in moderate poverty) (Social Development, 2014). Poverty goes hand in hand with food insecurity (Koch, 2011), especially during childhood. A substantial number of South Africans are still vulnerable to food shortage today (Koch, 2011; Oldewage-Theron et al., 2012). In spite of this food shortage, the obesity epidemic did not ironically spare South-Africa. The recent Lancet (2014) report identified South-Africa as the third fattiest country in the world. The country needs intervention and prevention programs. So we employed the pre-exposure procedure, which has 
been typically developed and tested on a well-fed population from industrialized countries. Since such procedure cannot just be exported to subsistence or transitional societies, we set out to test the effectiveness of the procedure.

Our results attest to the robustness of the pre-exposure procedure and shows that the procedure that exposes respondents to a temptation in a context that discourages its consumption is equally effective at reducing unhealthy food consumption in a population that has suffered from food insecurity. This study's findings add to the literature demonstrating that the preexposure procedure reduces the consumption of similar tempting foods in subsequent free consumption situations (Dewitte et al., 2009; Geyskens et al., 2008, Grubliauskiene \& Dewitte, 2015).

The pre-exposure procedure has also been found to work among children (de Boer et al., 2015, Grubliauskiene \& Dewitte, 2014), and now we have evidence that the effect can be applicable in developing countries, with high food insecurity. According to Peer et al. (2013), urban dwelling black young adults (15-24 years old), who represent the highest percentage of our sample (81.6\%), engage in unhealthy consumption lifestyle and are more at risk to noncommunicable chronic diseases (NCDs). It is interesting to note in our study that they could resist food temptation through the pre-exposure procedure.

Testing the pre-exposure procedure in a South-African context does more than show that the procedure is robust against the experience of food insecurity. Apart from childhood poverty and resultant food insecurity, South-Africans and Western societies differ on several other social and economic dimensions and arguably also on several cultural and socio-historic dimensions. Our findings revealed that irrespective of these differing factors, the pre-exposure procedure is robust. This suggests that it can be widely applied.

Zooming in on the moderating role of childhood poverty (Griskevicius et al., 2011), which we suggest is a proxy for childhood food insecurity since poverty prevents food access and proper food use (Oldewage-Theron et al., 2012), our data suggest that childhood poverty does not moderate the pre-exposure effect. Childhood poverty however had a good internal consistency in this sample and has been shown to have a broad impact on how people deal with adverse situations (Griskevicius et al., 2013). It is premature to draw strong conclusions from a non-significant finding in a relatively small sample like ours. It is nevertheless remarkable that 
the direction of the interaction suggests that, if anything, those with a poor background seem to be more, rather than less sensitive, to the pre-exposure effect.

This finding is reminiscent of de Boer et al.'s (2015) second study in which the strength of the behavioral conflict during the pre-exposure phase was directly manipulated. In that study, those who were instructed to think about the hedonic nature of the temptation during preexposure (strong conflict in phase 1), showed the strongest pre-exposure effect in the second phase. According to these researchers, the hedonic focus made the temptation stronger and hence required respondents to come up with stronger strategies to deal with the temptation. The strategies can be more easily accessible and applied later on, when the need arises.

We may speculate that childhood poverty, as a proxy for food insecurity, triggers a stronger motivation to eat in the first phase as well, and hence entails a stronger carry-over effect from the pre-exposure phase to the subsequent consumption phase. We call for further research to explore this possibility, which may make the pre-exposure procedure especially useful for a behavioral prevention model in regions where cheap Westernized diets arrive in a population for which food insecurity is a recent or even current threat.

The pre-exposure procedure is of course only an element and not a full blown prevention program. Its advantage is however that the procedure can be tested step by step, unlike full blown programs, which are very expensive and can leave the organizers clueless when they do not get the expected results. This was the case with the Discovery Health Insurance Healthyfood program in South-Africa. In about 800 supermarkets across South-Africa, Discovery Health Insurance gave 260,000 households $25 \%$ discount on the purchase of healthier food choices such as fruits, vegetables and wholegrain foods. A survey of 350,000 South-Africans four years later revealed that those who participated in the HealthyFood program, consumed less processed meats, fast-food, high sugar/salt and fried foods, and more fruits/vegetables and wholegrain foods. This change in consumption habit did not however reduce their level of obesity (An et al., 2013).

While we appreciate the applicability of the pre-exposure procedure in South-Africa, we call for further testing of the procedure in other countries poorer than South-Africa or among even poorer people in South Africa. We also call for studies that delve into the mechanism that 
underlies the pre-exposure effect [such as habituation (Epstein, Temple, Roemmich, \& Bouton, 2009)] in order to increase the scope and efficiency of the procedure or its compatibility with other procedures. Other moderators, such as cultural values and weight watching goals can be factored into the future testing of the pre-exposure procedure in poorer countries. There should also be an eye on designing highly effective and tailor-made health programs that can be finetuned to various target audience.

\section{References}

An, R., Patel, D., Segal, D., \& Sturm, R. (2013). Eating Better for Less: A National Discount Program for Healthy Food Purchases in South Africa. American Journal of Health Behaviour. 37(1), 56-61. doi: 10.5993/AJHB.37.1.6

Birrell, I. (2014). Obesity: Africa’s new crisis, The Observer, 21 September, 2014. http://www.theguardian.com/society/2014/sep/21/obesity-africas-new-crisis [accessed on November 24, 2014].

Brownell, K. , \& Horgen, K. B. (2004). Food Fight: The Inside Story of The Food Industry, America's Obesity Crisis and What We Can Do About It. Pediatrics, 133(1), 132.

Case, A., \& Menendez, A. (2009). Sex Differences in Obesity Rates in Poor Countries: Evidence from South Africa. Economics and Human Biology, 7(3), 271-282. doi:10.1016/j.ehb.2009

de Boer, C., de Ridder, D., de Vet, E., Grubliauskiene, A., \& Dewitte, S. (2015). Towards a Behavioral Vaccine: Exposure to accessible temptation when self-regulation is endorsed enhances future resistance to similar temptations in children. Applied Psychology: Health and Well-being, 7, 63-84.

De Vet, E., De Wit, J.B.F., Luszczynska, A., Stok. F.M., Gaspar, T., Pratt, M., Wardle, J., \& De Ridder, D.T.D. (2013). Access to excess: how do adolescents deal with unhealthy foods in their environment? European Journal of Public Health, 23, 752-756.

Dewitte, S., Bruyneel, S., \& Geyskens, K. (2009). Self-regulation enhances self-regulation in subsequent consumer decisions involving similar response conflicts. Journal of Consumer Research, 36 (October), $394-405$.

Epstein, L. H., Temple, J. L., Roemmich, J. N.; Bouton, M. E. (2009). Habituation as a determinant of human food intake. Psychological Review, 116, 384-407. 
Fishbach, A., Friedman, R. S., \& Kruglanski, A. W. (2003). Leading Us Not Unto Temptation: Momentary Allurements Elicit Overriding Goal Activation. Journal of Personality and Social Psychology, 84 (2), 296 -309.

French, S. A., Story, M. , Fulkerson, J. A. , \& Gerlach, A. F. (2003). Food Environment in

Secondary Schools: À La Carte, Vending Machines, and Food Policies and Practices.

American Journal of Public Health, 93(7), 1161-1168. doi: 10.2105/AJPH.87.5.849

Geyskens, K., Dewitte, S., Pandelaere, M., \& Warlop, L. (2008). Tempt Me Just a Little Bit

More: The Effect of Prior Food Temptation Actionability on Goal Activation and

Consumption. Journal of Consumer Research, 35, 600 - 610.

Griskevicius, V., Ackerman, J. A., Cantu, S. M., Delton, A. W., Robertson, T. E., Simpson, J. A., \& Tybur, J. M. (2013). When the economy falters, do people spend or save? Responses to resource scarcity depend on childhood environment. Psychological Science, 24, 197-205.

Griskevicius, V., Tybur, J. M., Delton, A. W., \& Robertson, T. E. (2011). The influence of mortality and socioeconomic status on risk and delayed rewards: A life history theory approach. Journal of Personality and Social Psychology, 100 (6), 1015 - 1026.

Grubliauskiene, A., \& Dewitte, S. (2014). Temptation in the background: Non-consummatory exposure to food temptation enhances self-regulation in boys but not in girls. Frontiers in Psychology, 5, 1-5.

Grubliauskiene, A. \& Dewitte, S. (2015). Triggering restriction goals during exposure to food temptations reduces their subsequent consumption in adults and children. Working paper at KU Leuven.

Hagger, M. S., \& Luszczynska, A. (2013). Implementation Intention and Action Planning Interventions in Health Contexts: State of the Research and Proposals for the Way Forward. Applied Psychology: Health and Well-Being, 10. DOI: 10.1111/aphw.12017

Hanekom, R., Venter, I., \& Toit, L (2014). Development of Food Knowledge Test for First-year Students at University of Technology in the Western Cape, South Africa, Journal of Family Ecology and Consumer Sciences, 42, 1-16.

Herman, C. P., \& Polivy, J. (2010). Sex and gender differences in eating behavior. In J.C. Chrisler \& D.R. McCreary (Eds.), Handbook of Gender Research in Psychology (455 469). Springer Science+Business Media.

Koch, J. (2011). The food security policy context in South Africa. International Policy Centre for Inclusive Growth. United Nations Development Programme, Available online: http://www.ipc-undp.org/publication/26788 [Accessed 25 November 2014]. 
Kroese, F. M., Evers, C., \& De Ridder, D. T. D. (2009). How chocolate keeps you slim. The effect of food temptations on weight watching goal importance, intentions, and eating behavior, Appetite 53 (3), 430-433.

Metcalfe, J., \& Mischel, W. (1999). A Hot/Cool-System Analysis of Delay of Gratification: Dynamics and Willpower. Psychological Review, 106 (1), 3-19.

Oldewage-Theron, W. H., Duvenage, S. S., \& Egal, A. A. (2012). Situation Analysis as indicator of food security in Low-income Rural Communities. Journal of Family Ecology and Consumer Sciences, 40, 38-58.

Peer, N., Bradshaw, D., Lauscher, R., Steyn, N. \& Steyn, K. (2013), Urban-rural and gender differences in tobacco and alcohol use, diet and physical activity among young black South Africans between 1998 and 2003. Global Health Action, 6, doi: 10.3402/gha.v6i0.19216

Peltzer, K. (2004). Nutrition knowledge among a sample of urban black and white South Africans. South African Journal of Clinical Nutrition 17(1), 24-31.

Popkin B. M., Adair L. S., \& Ng S.W. (2012). Global nutrition transition and the pandemic of obesity in developing countries, Nutrition Reviews, 70(1), 3-21. doi: 10.1111/j.17534887.2011.00456.x.

Social Development (2014). Poverty levels in South Africa dropping, Available online: http://www.southafrica.info/about/social/poverty040414.htm\#.VG5NbfnF_vk\#ixzz3Jdv00 2kT (accessed November 20, 2014).

Trope, Y., \& Fishbach, A. (2000). Counteractive self-control in overcoming temptation. Journal of Personality and Social Psychology, 79, 493-506.

The Lancet, (2014). Global, regional, and national prevalence of overweight and obesity in children and adults during 1980-2013: a systematic analysis for the Global Burden of Disease Study 2013, 384 (945), 766-781. doi:10.1016/S0140-6736(14)60460-8 http://www.thelancet.com/journals/lancet/article/PIIS0140-6736(14)60460-8/abstract [accessed on November 24, 2014].

Van der Berg, S. (2014). Inequality, poverty and prospects for redistribution, Development Southern Africa, 31 (2), 197-218. 